\title{
PREPARATION AND PROPERTIES OF PURE IRON ALLOYS: III. EFFECT OF MANGANESE ON THE STRUCTURE OF ALLOYS OF THE IRON-CARBON SYSTEM.
}

By Henry S. Rawdon and Frederick Sillers, jr.

\begin{abstract}
.
Manganese plays at least three distinct rôles in carbon steels-as deoxidizer, "desulphurizer," and as a hardening element. This article is concened with the last function. The effect of manganese upon the structure, and hence upon the properties, of iron-carbon alloys was determined in an extensive series of alloys varying from $\circ$ to r.6 per cent carbon and $\circ$ to 2 per cent mangagese in the annealed and the normalized condition. The effect of manganese may be described as a "restraining" influcnce, so that pearlite in carbon steels even after annealing has a fine-grained sorbitic structure such as results ordinarily upon more rapid cooling. The mechanical properties are correspondingly raised. The eutectoid ratio of carbon steels is lowered by manganese from 0.90 per cent carbon to approximately 0.78 per cent by I per cent manganese. In the annealed alloys manganese appears to have no influence on grain size; in specimens which were cooled more rapidly-that is, normalized-the grains of the alloys of high manganese content were very much smaller than in similar alloys of lower manganese. This structural feature also has its effect upon the mechanical properties.
\end{abstract}

\section{CONTENTS.}

Introduction .

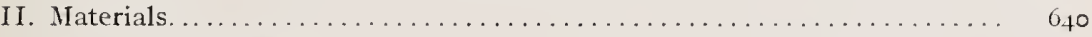

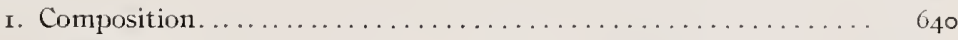

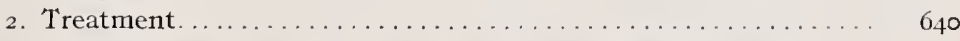

III. Structural features resulting from variations in manganese contents..... $6_{42}$

I. Annealed alloys. . . . . . . . . . . . . . . . . . . . . . 642

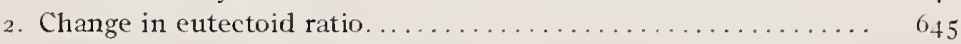

3. Normalized specimens. . . . . . . . . . . . . . . . . 645

IV. Discussion ........................................ $6_{50}$

V. Summary............................................ 653

\section{INTRODUCTION.}

Although the influence of manganese as a "hardening element" of steel, in addition to its action as a deoxidizing and "desulphurizing" agent, is well understood by metallurgists, it is doubtful whether its behavior in this respect is fully appreciated by designing engineers and users of steel in general. In a previous publi- 
cation of the Bureau of Standards ${ }^{1}$ the preparation of a series of iron-carbon-manganese alloys has been described, together with their utilization for the determination of the specific effect of carbon and of manganese upon the mechanical properties of such alloys. The scope of the present article is restricted to a discussion of the structural effects resulting from variations in the manganese content and is based upon a study of the alloys prepared in the former investigation. These alloys were of a very high degree of purity. The materials used in their preparation were electrodeposited iron, manganese of 98.75 per cent purity, and an iron-carbon alloy ( 4.5 per cent carbon) prepared from Acheson graphite and some of the electrodeposited iron. Crucibles of fused magnesia prepared especially for this investigation were used for containing the alloys during the melting, which was carried out in vacuo. The following figures show the maximum impurities in any of the finished alloys: Sulphur, o.0o8 per cent; silicon, 0.008 per cent; nickel, copper, and cobalt (combined), $0.01+$ per cent.

The conclusions reached by Neville and Cain, as a result of their investigation of the series of iron-carbon-manganese alloys prepared from pure materials, concerning the effect of residual manganese upon the tensile properties and hardness may be summarized as follows:

The effects of carbon and of manganese are mutually dependent upon each other-the presence of carbon augments the influence of manganese, and vice versa. The ultimate tensile strength of the alloys was found to increase by an amount varying from 90 to $25^{\circ} \mathrm{lbs}$. $/$ in. ${ }^{2}$ for each addition of 0.01 per cent manganese, the lower rate of increase being for the alloys of low-carbon content. The proportional limit was found to be affected in much the same way as the ultimate tensile strength by variations in the manganese, whereas the ductility was only slightly affected. The average increase in the Brinell hardness number for each o.or per cent addition of manganese is 0.5 , though for low-carbon alloys it is somewhat less than this value.

As illustrative of the effects of manganese upon the mechanical properties of commercial carbon steels in the normalized state, the following values (Table 1 ) given by Aitchison, ${ }^{2}$ may be cited.

\footnotetext{
1 R. P. Neville and J. R. Cain, "The preparation and properties of pure iron alloys: I. The effect of carbon and manganese on the mechanical properties of pure iron," B.S.Sci. Papers, no. 453, 1922. The paper contains a rather complete bibliography on the effect of manganese on carbon steels.

${ }^{2}$ I. Atchison, "Engineering steels," p. $x_{43}$ D. Van Nostrand Co., 1923.
} 
TABLE 1.-The Effect of Manganese on the Tensile Properties of Commercial Carbon Steel.

\begin{tabular}{|c|c|c|c|c|c|}
\hline & Carbon (per cent). & $\begin{array}{l}\text { Mangan- } \\
\text { ese. }\end{array}$ & $\begin{array}{l}\text { Yield } \\
\text { point. }\end{array}$ & $\begin{array}{c}\text { Maximum } \\
\text { tensile } \\
\text { strength. }\end{array}$ & $\begin{array}{c}\text { Elonga- } \\
\text { tion. }\end{array}$ \\
\hline $\begin{array}{r}0.21 \\
.25 \\
.38 \\
.36\end{array}$ & & $\begin{array}{r}\text { Per cent. } \\
0.05 \\
.85 \\
.08 \\
.58\end{array}$ & $\begin{array}{r}\text { Lbs./in. }{ }^{2} \\
38,100 \\
56,000 \\
44.800 \\
58.300\end{array}$ & $\begin{array}{r}\text { Lbs. in. }{ }^{2} \\
56.000 \\
60.500 \\
67.200 \\
78.400\end{array}$ & $\begin{array}{r}\text { Per cent. } \\
42 \\
30 \\
35 \\
28\end{array}$ \\
\hline $\begin{array}{l}.37 \\
.49 \\
.47 \\
.50\end{array}$ & & $\begin{array}{l}.82 \\
.09 \\
.70 \\
.80\end{array}$ & $\begin{array}{l}60.500 \\
49.300 \\
65.000 \\
67,200\end{array}$ & $\begin{array}{r}96,300 \\
80,600 \\
94,100 \\
112.000\end{array}$ & $\begin{array}{l}25 \\
27 \\
26 \\
20\end{array}$ \\
\hline
\end{tabular}

The general effect of manganese upon the structure, and hence the properties, of carbon steels has been well expressed by Howe ${ }^{3}$ as follows: "Its effect on the mechanical properties of the steel scems to me in the last analysis due primarily to its retarding action on the transformations and on the coalescence of the microconstituents into progressively coarser masses ***. The retarding effect on the structural changes shows itself by leading in general (in carbon steels) to finer structure, finer ferrite masses, finer network structure, and finer pearlite, indeed, probably often to the replacement of lamellar pearlite with sorbite. This greater fineness leads to better quality in general and to a higher elastic limit in particular, though, of course, with a corresponding sacrifice in ductility. The great value of manganese for this purpose has not begun to receive the attention it deserves."

The series of iron-carbon-manganese alloys available offered an excellent opportunity for studying the structural changes in carbon steels which result from manganese, a study which, on account of the dearth of information along this line in the technical literature, is very desirable. Although the alloys belong to the ternary system, the most convenient and practical way to treat them, so far as their relation to steel is concerned, is to regard them as belonging to the binary or iron-carbon series, with manganese as an extraneous or added element. This is the general method used in the following discussion.

\footnotetext{
${ }^{3}$ H. M. Howe, Topical discussion on the roble of the general alloying elements in the alloy steels, "'rhe rile of manganese" ; A.S. T. M. Proc., 17, p. 5; 1917.
} 


\section{MATERIALS. \\ 1. COMPOSITION.}

In Figure $\mathrm{I}$ are indicated the alloys available for examination, grouped according to the respective carbon and manganese contents. One hundred and two alloys with carbon varying from o to 1.6 per cent, and manganese varying from o to 2 per cent, were used. Although the structures of all of the specimens shown were examined, micrographs of only a few have been reproduced as types in the following discussion. Such

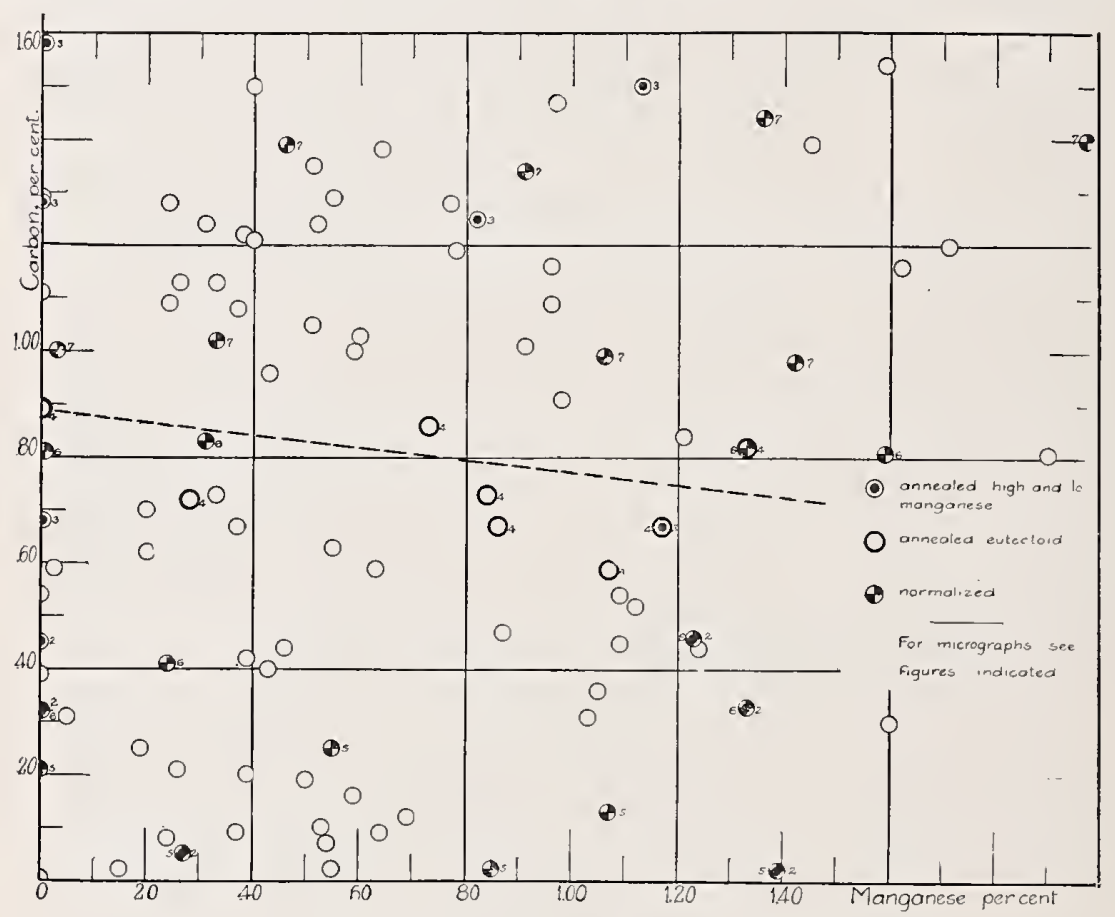

FIG. I.-Series of iron-carbon-manganese alloy's examined.

specimens have been suitably indicated in Figure 1 , and the carbon and manganese content given on the respective micrographs in the different figures. The results of the complete chemical analysis of all the specimens are given in the reference cited above. ${ }^{4}$

\section{TREATMENT.}

In the previous investigation all of the specimens were heat treated before being tested. This treatment varied somewhat according to the composition of the alloy, the aim being to 
develop the highest tensile properties in the normalized condition. On account of the relatively small size of the ingots, approximately 8 by $\mathrm{I}, 2 / 2$ inches, the reduction during the mechanical working of the metal was not sufficient to remove entirely the "ingot structure." Hence, a preliminary annealing was given all of the specimens after being cut from the rolled plate in order to minimize any possible "ingotism" remaining. 'The bars were heated for two hours at the annealing temperature, which was varied according to carbon content, as follows: Carbon o to 0.09 per cent, $940^{\circ} \mathrm{C}$; o.Io to 0.29 per cent, $900^{\circ} \mathrm{C}$.; 0.30 per cent, $840^{\circ} \mathrm{C}$.; after this they were allowed to cool in the furnace.

In carrying out the normalizing treatment which followed the preliminary annealing, allowance was made for the differences in both carbon and manganese contents. The treatments are summarized in Table 2.

TABLE 2.-Normalizing Treatment (20 Minutes at Required Temperature, Followed by Air Cooling).

\begin{tabular}{|c|c|c|c|c|c|}
\hline \multirow{2}{*}{ Carbon (per cent). } & \multicolumn{2}{|c|}{$\begin{array}{l}\text { Temperature }{ }^{\circ} \mathrm{C} \text {. } \\
\text { according to } \\
\text { manganese } \\
\text { content. }\end{array}$} & \multirow{2}{*}{ Carbon (per cent). } & \multicolumn{2}{|c|}{$\begin{array}{l}\text { Temperature }{ }^{\circ} \mathrm{C} \text {. } \\
\text { according to } \\
\text { mangan s } \mathrm{e} \\
\text { content. }\end{array}$} \\
\hline & $\underset{0 \text { to } 0.79}{\mathrm{Mn}}$ & $\frac{\mathrm{Mn}}{0.80 \text { to } 1.50}$ & & $\begin{array}{c}\mathrm{Mn} \\
0 \text { to } 0.79\end{array}$ & $\underset{0.80 \text { to } 1.50}{\mathrm{Mn}}$ \\
\hline 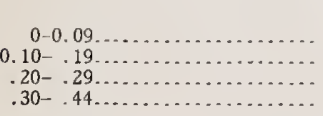 & $\begin{array}{r}\text { Per cent. } \\
940 \\
915 \\
885 \\
845\end{array}$ & $\begin{array}{r}\text { Per cent. } \\
915 \\
885 \\
860 \\
830\end{array}$ & $\begin{array}{l}0.45-0.59 \ldots \ldots \ldots \\
.60-.74 \ldots \ldots \ldots \\
.75-1.50 \ldots \ldots\end{array}$ & $\begin{array}{r}\text { Per cent. } \\
815 \\
785 \\
770\end{array}$ & $\begin{array}{r}\text { Per cent. } \\
800 \\
785 \\
770\end{array}$ \\
\hline
\end{tabular}

In addition to examining all the specimens in the normalized condition, many of them were reexamined after a second or supplementary annealing. Small pieces approximately $\mathrm{I}_{5} \mathrm{~g}$ in mass, cut from the ends of broken tension specimens, were packed in an iron container (section of 3 -inch pipe) covered with amorphous silica containing a small amount of charcoal and heated to a temperature of approximately $750^{\circ} \mathrm{C}$. $\left(745\right.$ to $765^{\circ} \mathrm{C}$.). After a sojourn of one hour at this temperature, the container and specimens were allowed to cool rather slowly within the furnace, one hour being required for the temperature to drop from 750 to $600^{\circ} \mathrm{C}$. In this examination, since all of the specimens had received identical treatments, the effect of the manganese upon the structure was much more evident and permitted closer comparison than in the same samples after the normalizing treatment. 


\section{STRUCTURAL FEATURES RESULTING FROM VARIA- TIONS IN MANGANESE CONTENTS.}

1. ANNEALED ALLOYS.

In Figures 2 and 3 are shown the structures of a series of alloys of progressively increasing carbon contents, each one of which occurred in combination with a low and a high manganese content (see Fig. 1). The characteristic influence of the manganese in the steel which resulted in the pearlite being in a fine-grained sorbitic state rather than in the coarser lamellar condition is very evident in these micrographs. The general appearance of the alloys of high manganese content is similar to that which would result in the companion-that is, the low manganese-alloy if it were cooled at a much more rapid rate than was used here.

The results obtained with the annealed alloys indicated that manganese has very little, if any, effect upon the grain size of the annealed material. This conclusion is not in entire agreement with that reached by Howe, ${ }^{5}$ that manganese decreases the size of the austenite crystals and therefore the size of ferrite network in the annealed steel resulting from them. However, as will be shown later, steels of high manganese content when cooled at a more rapid rate, for example in normalizing, often are of a much finer grain structure than steels of similar carbon content but lower in manganese. This is the condition which obtains more frequently in commercial steels than that shown by the slowly cooled alloys in Figures 2 and 3, and hence may account for the conclusion reached by Howe concerning the effect of manganese upon grain size.

TABLE 3.-Effect of Manganese on the Brinell Hardness of the Annealed Alloys.

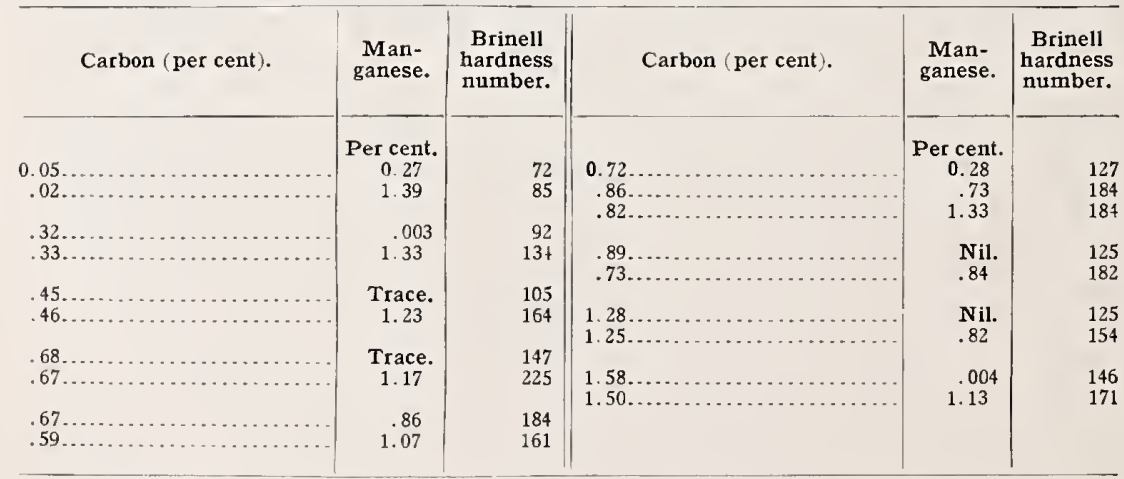

sSee footnote 3 ; also H. M. Howe, "Life history of network and ferrite grains in carbon steel," A. S. T. M. Proc., 11, p. 365 ; $191 \mathrm{x}$. 

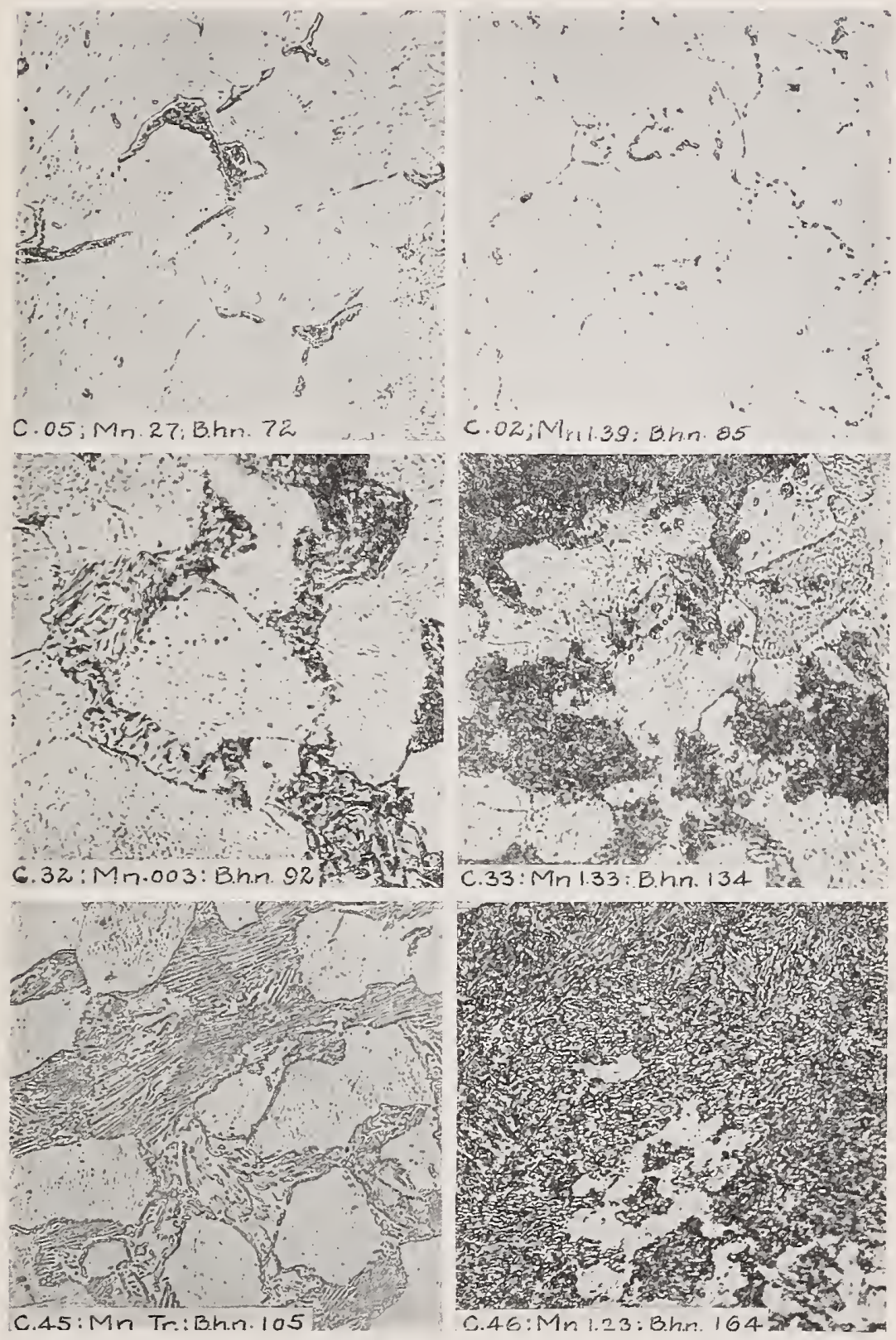

FIG. 2.-Microstructure of annealed alloy's of similar carbon content with low and with high manganese. Note the pronounced difference in the character of the pearlite which results from an increase in the manganese content. $\times 500$. 

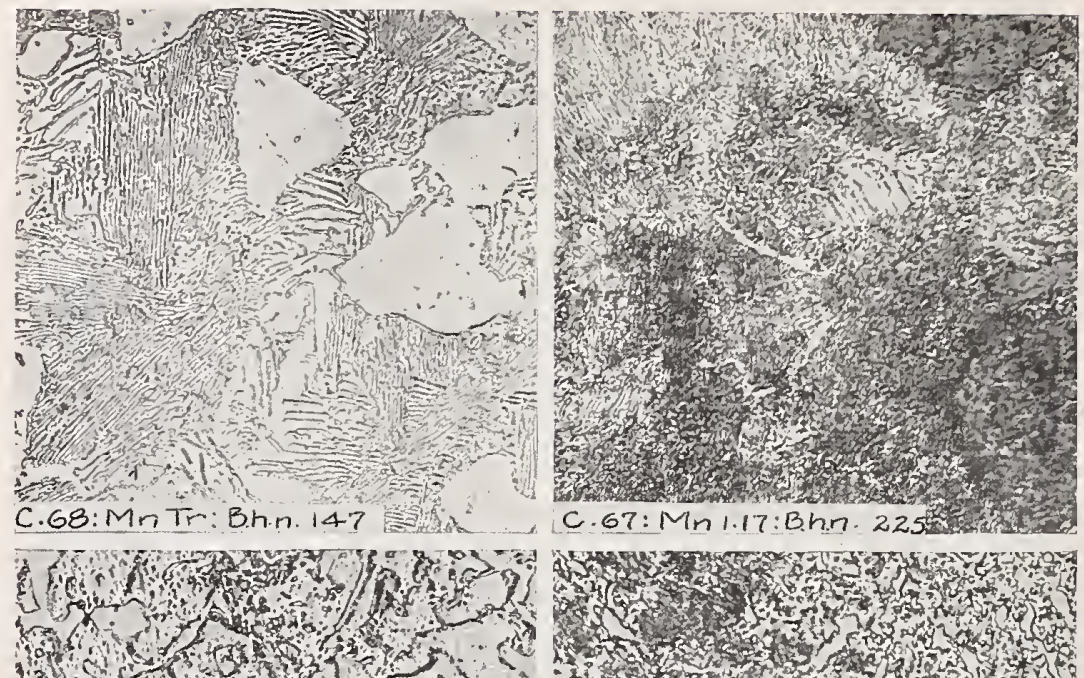

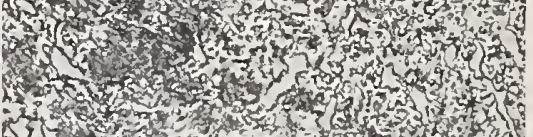

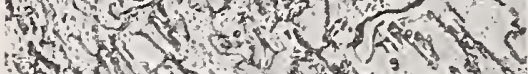

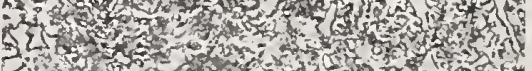

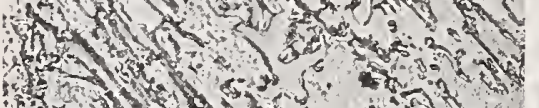

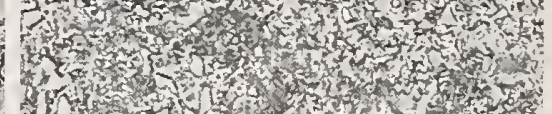

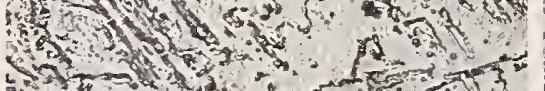

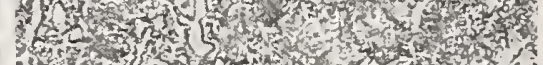
(x)

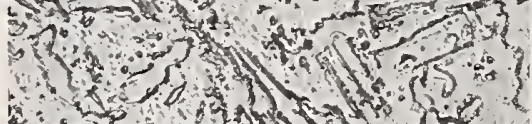

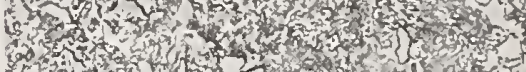

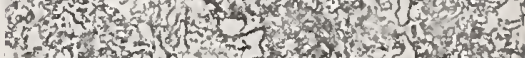

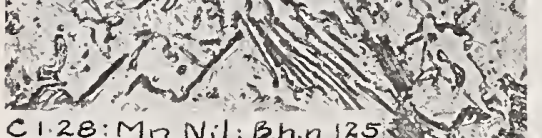

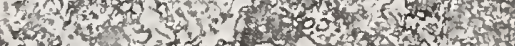

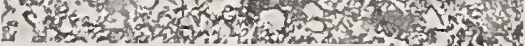

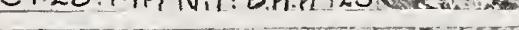
C $1.25: M n .82:$ :hn 154 het
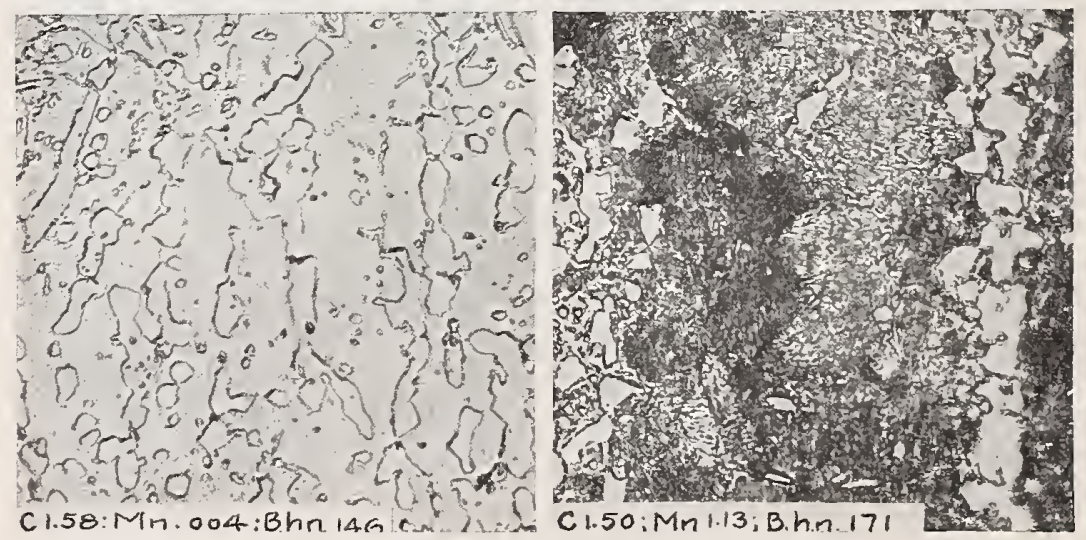

Fig. 3.-Microstructure of annealed alloys shawing the changes resulting from variations in the manganese content in spccimens of similar carbon content. $\times 500$. 
As an indication of the effect of manganese upon the mechanical properties of the alloys in the annealed state the Brinell hardness was determined, a "micro-Brinell" set which employs a onesixteenth-inch diameter ( $\mathrm{I} .5^{8} \mathrm{~mm}$ ) ball and a $5^{-} \mathrm{kg}$ load being used. The results are summarized in Table 3 ; the hardness has also been indicated on the micrograplis of these alloys.

\section{CHANGE IN EUTECTOID RATIO.}

In addition to the difference in the character of the pearlite resulting from the presence of manganese another noticeable structural change is the decrease in the amount of precipitated proeutectoid ferrite in all of the alloys containing manganese. This condition implies a change in the eutectoid ratio, the "pearlite point" being gradually shifted to the left; that is, to lower carbon percentages by the addition of manganese. Further substantiating evidence of this is afforded by the fact that free cementite may be detected in alloys containing considerable manganese but with a carbon content somewhat below the eutectoid composition of the simple iron-carbon alloys (Fig. 4).

By the examination of a series of annealed specimens of approximate eutectoid composition the location of the apparent eutectoid line was determined and has been indicated in Figure I. Figure 4 shows the microstructure of the series of entectoid alloys examined after annealing. The presence of free ferrite or cementite is the criterion used in reaching a decision as to upon which side of the line the alloy should be placed. By this means the dashed line shown in Figure I was located. This indicates that I per cent of added manganese lowers the eutectoid ratio to approximately 0.78 per cent carbon.

The line as drawn represents the structural conditions which obtain under ordinary circumstances. The exact or theoretical location of the line is a matter of considerable uncertainty, since the degree of annealing would have to be varied to suit the variations in manganese content of each of the different alloys.

\section{NORMALIZED SPECIMENS.}

From the numerous specimens examined in the normalized condition, a few typical samples of the various grades according to carbon content were selected, micrographs of which have been given in Figures 5, 6, and 7. In addition to the characteristic effect of manganese upon the nature of the pearlite, which was even more evident here than it was in the annealed specimens, these micrographs indicate that the grain size of hypoeutectoid 

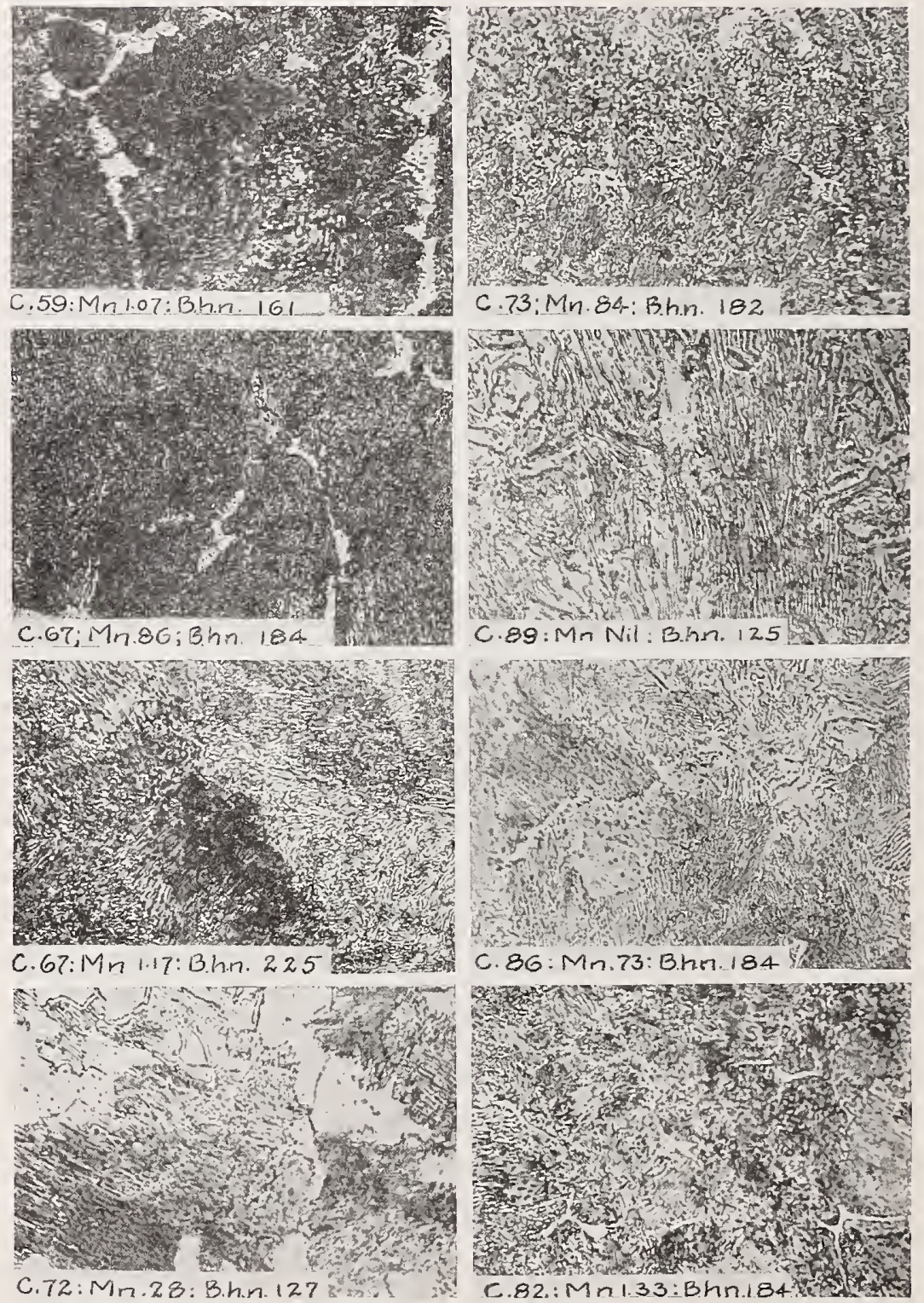

FIG. 4.-Nicrostructure of anncaled alloys of approximately eutectoid composition showing the changes rosulting from variations in manganese content. See Figure I for the location of eutectoid line. $\times 500$. 


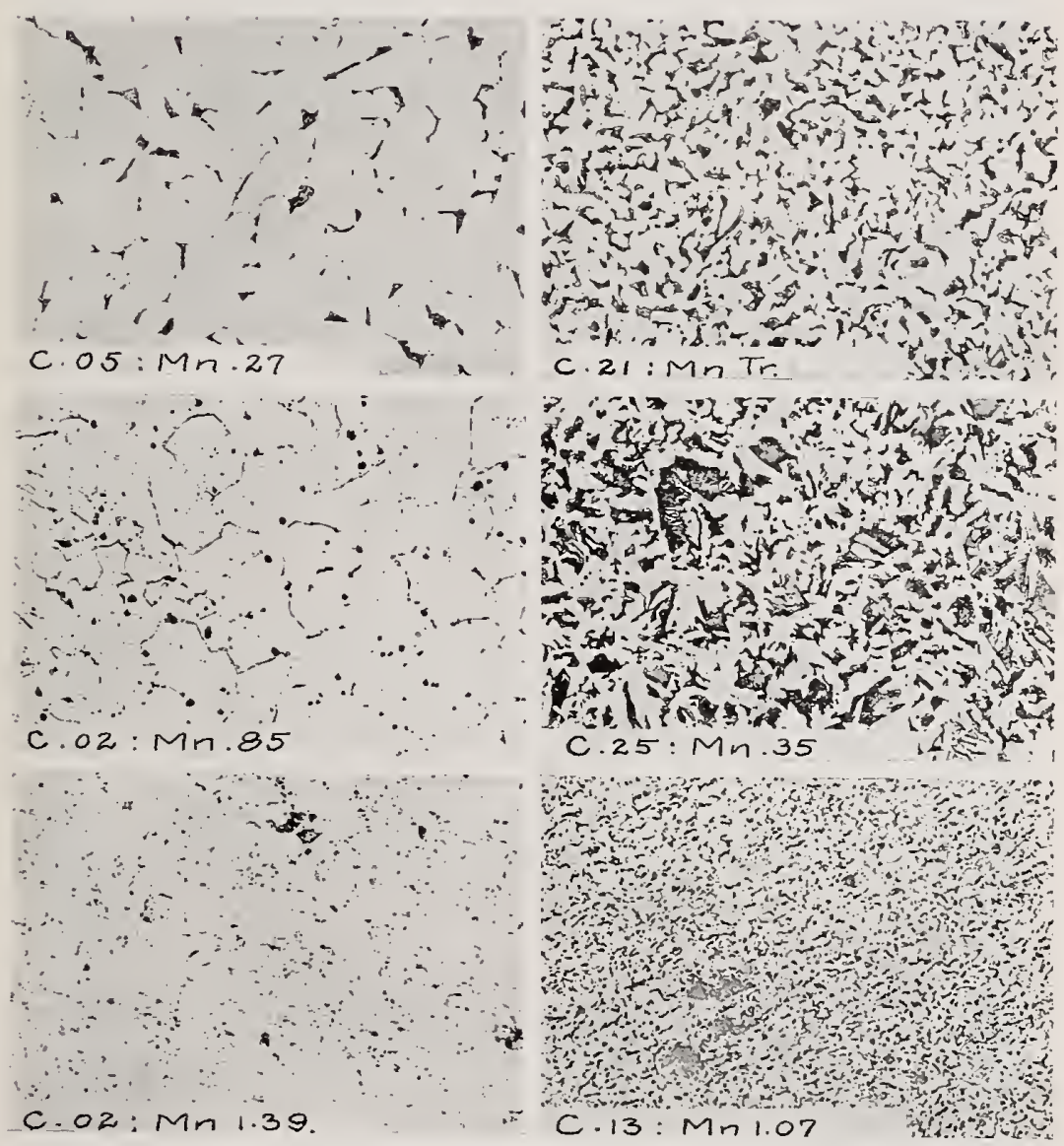

FIG. 5.-Microstructural changes produced by variations of the manganese content of normalized alloy's of low carbon content. Note the decrease in grain size with increasing manganese. $\times$ Ioo. 

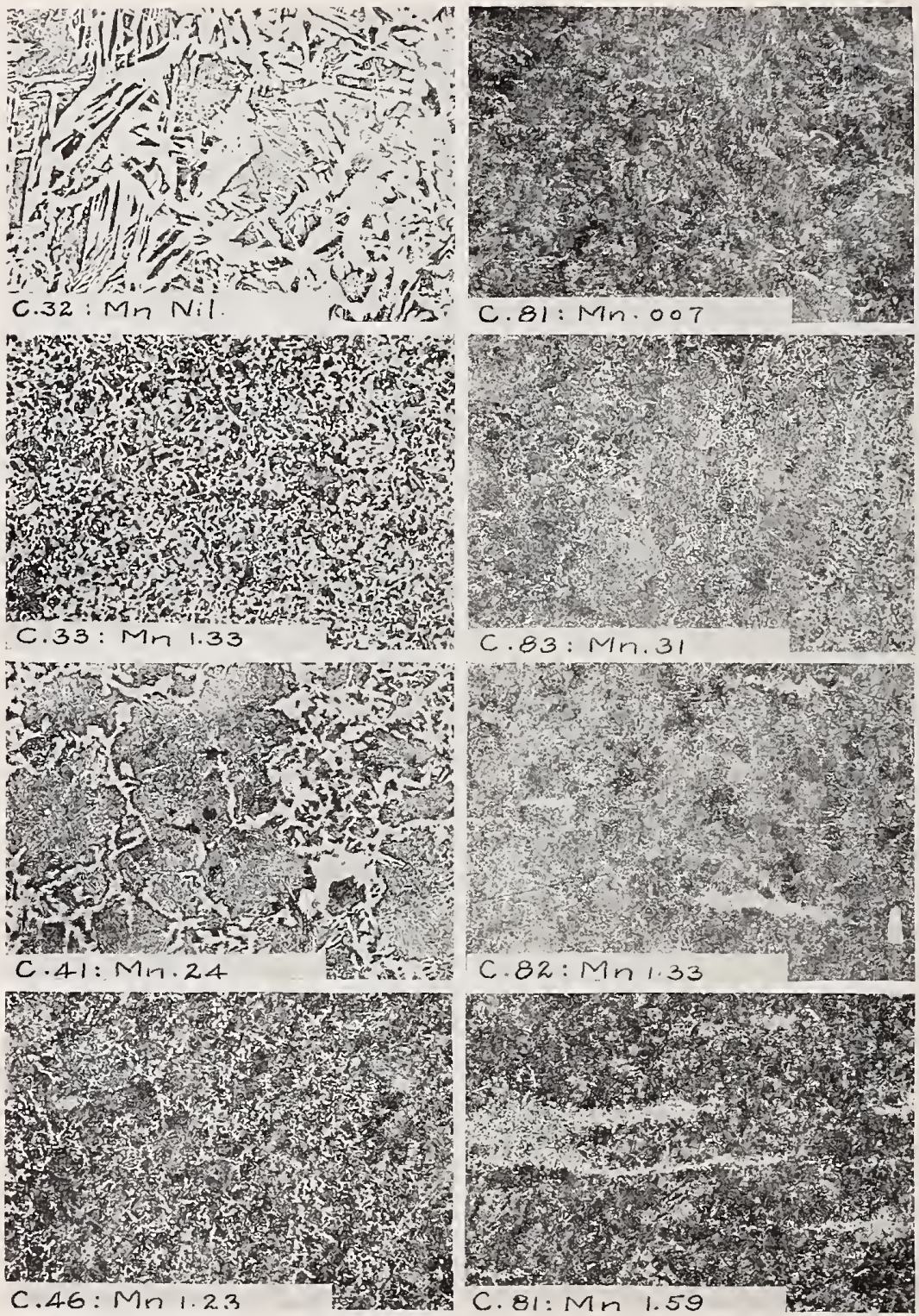

FIG. 6.-Microstructural changcs produced by variations in the manganese content of normalized alloy's of medium and of eutectoid carbon content. Note the change in grain size of the medium carbon allols. $\times$ Ioo. 

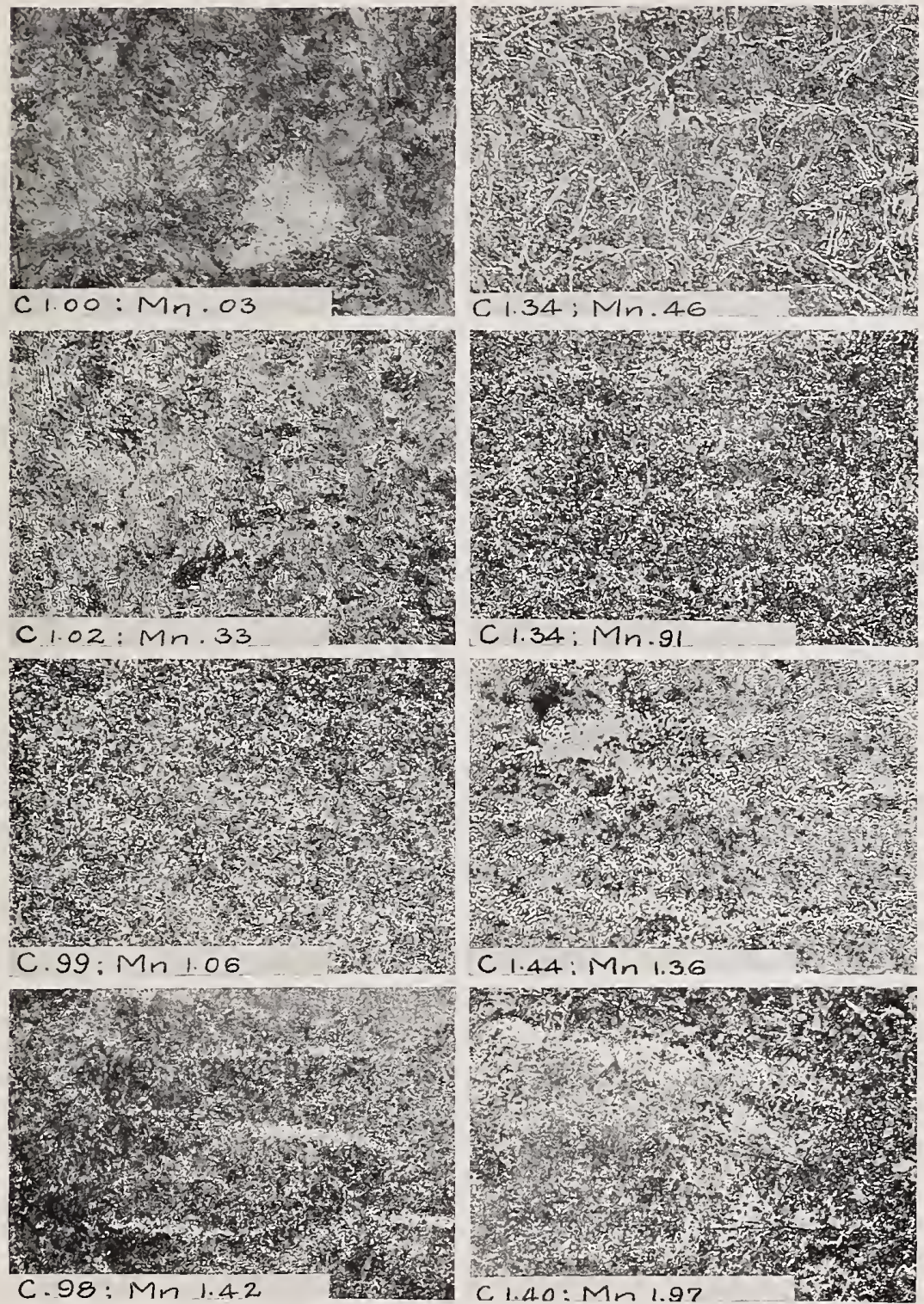

Fig. 7.-Microstructural changes in normalized high carbon alloys resulting from variations in the manganese content. Note the gradual increase in amount and. change in character of the cementite. $\times$ Ioo. 
steels when cooled fairly rapidly - that is, normalized-is apparently considerably less in those of high manganese content than in similar ones lower in manganese. The ferrite masses in the steels of high manganese content are much smaller and the continuity of the pearlite grains is broken up much more effectively than in the similar steels of lower manganese content.

In the high-carbon steels an increase in manganese content leads to formation of cementite in excess of that which normally occurs in simple carbon steels of the same carbon content. Instead of the well-defined plates, in which form cementite often appears in high-carbon steels, manganese causes this constituent to occur in very much smaller masses or granules. In some of the specimens prominent, 'well-defined streaks of cementite were found. It is believed, however, that this structural feature was a result of the small-scale production used in the preparation of these alloys and that it may not be a characteristic effect of manganese in general.

\section{DISCUSSION.}

The effect of manganese in lowering the "critical" or the transformation temperatures of steel is well known. The magnitude of this effect upon the $\mathrm{Ar}_{1}$ transformation in iron-carbon alloys ( + per cent carbon or above) has been stated by IVust ${ }^{6}$ to be 20 to $25^{\circ} \mathrm{C}$. for each per cent of manganese added, provided the total amount is not in excess of 5 per cent. The more recent investigation by Matsushita ${ }^{7}$ of low-carbon steels (approximately 0.2 I per cent carbon) indicates the lowering of the $\mathrm{Ar}_{1}$ temperature for each per cent of added manganese, up to a total of 9.8 per cent of this element, to be slightly less than $20^{\circ} \mathrm{C}$.

The structural changes in the character of the pearlite of the alloys previously described can, in large measure, be accounted for by the effect of this element upon the transformation temperatures. However, the fact that all elements which lower the $\mathrm{Ar}_{1}$ transformations in steel do not produce the same change in structure of the annealed pearlite indicates that the result is dependent to some extent upon other factors. This characteristic effect of manganese has been well stated by Howe ${ }^{8}$ as follows: "Sluggishness from lowering the birth temperature of ferrite and pearlite reinforces sluggishness due directly to the presence of manganese."

\footnotetext{
${ }^{6}$ F. Wust, "Beitrag zum einfluss des mangans auf die system eisen-kohlenstoff," Metallurgie, 6, p. 3; I909.

T'T. Matsushita, "Influence of manganese on the physical properties of carbon steels," Science Reports, Tohôku Univer ity, Sendai, Japan, 8, p. 79; I9rg.

${ }^{8}$ See footnote 5 .
} 
Manganese and iron are completely isomorphous and hence form a continuous series of solid solution. In the ternary ironcarbon-inanganese alloys of low-carbon content it is probable then that at least part of the manganese exists in solid solution in the ferrite. Manganese also reacts with carbon to form a carbide corresponding to cementite, so that in the alloys of higher carboin content it may be expected that the manganese exists in the form of carbide. Whether a double carbide of iron and manganese or a mixture of the simple carbides of the two elements exists is still an open question. Although each of these two factors, the solution of manganese in ferrite and the presence of a special carbicle of this element, undoubtedly has an effect upon the mechanical properties of the steel, it appears very probable that the structural effect resulting from the presence of manganese is of much greater importance in this respect.

An indication of the magnitude of the effect resulting from the solution of manganese in ferrite is given by the very low-carbon alloys in Table 3 . It will be noted that the increase in hardness produced by manganese in this case was very much less than in those in which more carbon was present, and hence a greater structural difference existed between the low and high manganese alloys.

Concerning the effect of manganese upon the grain size of steel, conflicting statements have appeared in the technical literature. Howe $^{9}$ attributed much of the beneficial effect of manganese in low-carbon steels to a decrease in the grain size resulting from the presence of this element. Hoyt ${ }^{10}$ states that no marked difference in ferrite grain size results from the presence of manganese in steel. The results obtained in this investigation indicate that the rate at which the steel is cooled is a very important factor in this respect. In the annealed alloys of high and low manganese content no noticeable difference in grain size could be detected. However, in the same or similar alloys which had been given a normalizing treatment, and hence cooled much more rapidly, the difference in grain size was very marked, the grain size being very much less in those containing the higher percentages of manganese. The marked difference in Brinell hardness observed in the high and low manganese alloys after annealing indicates, however, that any increase in the mechanical properties as a result of the decreased grain size in the materials of relatively high-manganese content

9 See footnote 3 .

10 S. I. Hoyt Metallography, Part II, "The metals and common alloys," p. 340; 192 I. 
is in addition to the effects which are induced directly by the presence of manganese.

Another effect of manganese in steels is the shift in the eutectoid ratio toward the left of the diagram; that is, to a lower percentage of carbon. An addition of I per cent of manganese in the ironcarbon alloys examined lowered the eutectoid ratio to approximately 0.78 per cent carbon. This change is considerably greater than the value quoted by Hoyt, ${ }^{11}$ a lowering to 0.75 per cent carbon for 2 per cent manganese being given by him. The very fine grained or sorbitic character of the pearlite in alloys containing considerable manganese, together with the ready tendency toward spheroidization of the lamellar pearlite of manganese-free alloys, renders the location of the eutectoid line a matter of considerable uncertainty. By cooling the manganese alloys from the annealing temperature at a very much slower rate than the one employed, this line might be located somewhat more accurately. However, the position given in the diagram (Fig. I) represents very closely the conditions which obtain in commercial practice.

One other practical effect of manganese in steel as indicated by the foregoing micrographs is the decrease in spheroidization of the cementite. The large amount of cementite remaining in the sorbitic condition in the high-carbon alloys containing considerable manganese is a very conspicuous feature of the structure as compared with similar low-manganese alloys which received the same treatment.

The value of manganese as a strengthening element in carbon steels, particularly in those of low-carbon content, has been emphasized by prominent metallurgists, for example Howe, and to some extent such steels are now used commercially, especially abroad. While the results of structural examination alone, such as this article describes, will not permit of any definite recommendation in this respect, it is very evident from the results described above that by the use of higher manganese contents than are usually employed a structural condition may be obtained in low and medium carbon steels which is very much more desirable than that which obtains in a similar steel but of lower manganese content after having received an identical treatment. The results strongly support the recommendations which have been made at different times concerning the advantages to be gained by using higher manganese in such steels. 


\section{SUMMARY.}

1. The investigation, which is part of the general study of the iron-carbon-manganese alloys which is being conducted by the Bureau of Standards, consisted of a study of the microstructure of a comprehensive series of these alloys. One hundred and two alloys with carbon varying from o to 1.60 per cent, and inanganese varying o to 2 per cent were used.

2. The effect of manganese as observed in annealed alloys is to confer upon the pearlite a very fine grained or sorbitic structure, even after slow cooling. The relative amount of pearlite present is considerably greater in the alloys of high manganese content than in corresponding ones low in this element. A pronounced increase in Brinell hardness of the annealed alloys accompanies the change in structure produced by the addition of manganese.

3. The addition of manganese causes a shift in the entectoid ratio toward lower-carbon content. One per cent of manganese lowers it to approximately 0.78 per cent carbon.

4. In the normalized alloys a pronounced decrease in grain size was found in those of higher manganese contents, in addition to the structural effects mentioned above. In the annealed specimens no noticeable difference in grain size was detected for high and low manganese content in alloys of any given carbon content.

5. The well known effect of manganese in lowering the transformation temperatures of the materials will account in part for observed structural changes. It appears also that manganese renders steel more "sluggish" and less responsive to structural changes than many of the other elements which produce a similar lowering of the critical temperatures.

6. While the results of the structural examination will not warrant any definite conclusions concerning the use of manganese as a strengthening element in steel, the results obtained strongly support previous recommendations which have been made by different metallurgists concerning the advantages to be gained from the use of higher manganese, particularly in low and medium carbon steels.

Washington, September 23, I922. 



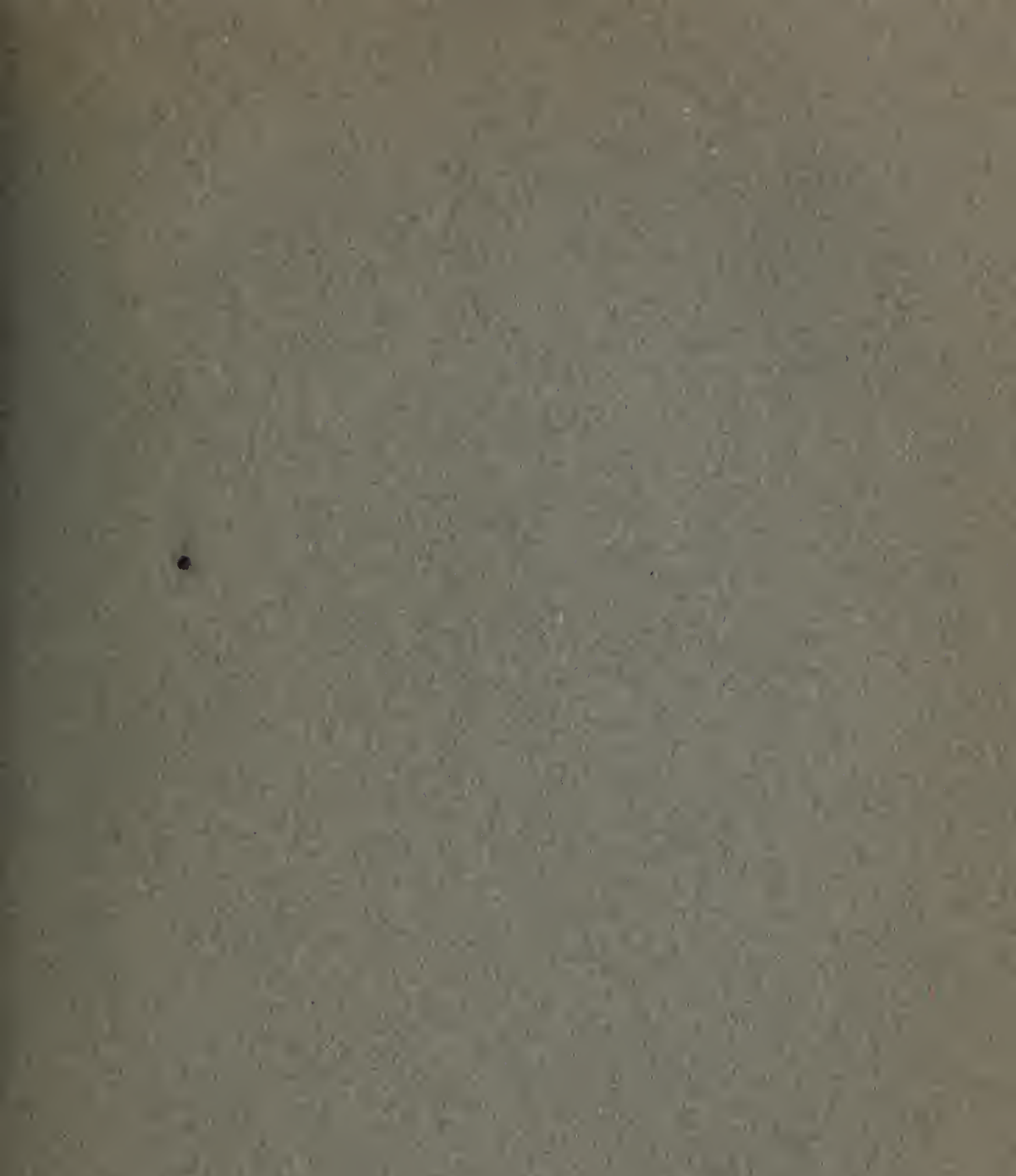
Q

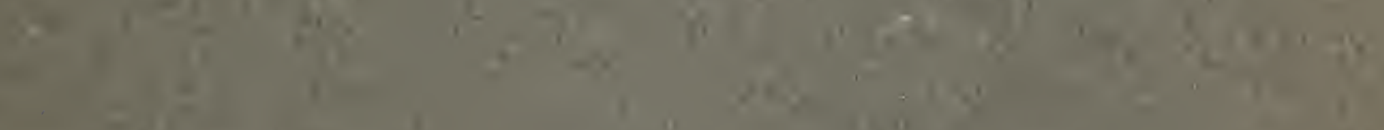

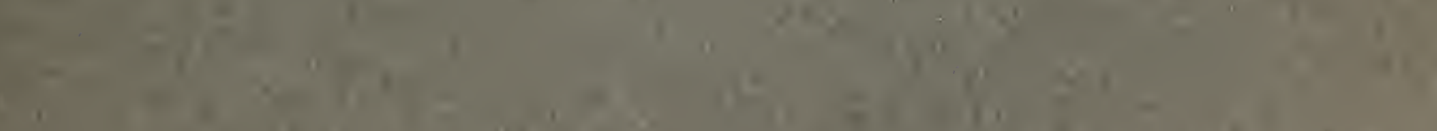


